\title{
Original Article Major Characteristics of Surface Sediments Within the Shallow Water of the Cat Ba Island, North Vietnam
}

\author{
Nguyen Huy Hoang ${ }^{1}$, Bui Van Vuong ${ }^{1}$, Evgenii Egidarev ${ }^{2}$, Vasiliy Zharikov², \\ Le Anh Xuan ${ }^{1}$, Lai Thi Bich Thuy ${ }^{3}$, Nguyen Thi Mai Luu ${ }^{1}$, Nguyen Dac Ve ${ }^{1}$, \\ Duong Thanh $\mathrm{Nghi}^{1}$, Dang Hoai Nhon ${ }^{1, *}$ \\ ${ }^{1}$ Institute of Marine Environment and Resources, Vietnam Academy of Science and Technology, \\ 246 Da Nang, Hai Phong, Vietnam \\ ${ }^{2}$ Pacific Geographical Institute, Russian Academy of Sciences, 7 Radio, Vladivostok, Russia \\ ${ }^{3}$ Center for Geological Experiment Analysis, Ministry of Natural Resources and Environment, \\ Km9, Nguyen Trai Ha Dong, Ha Noi, Vietnam
}

Received 06 May 2020

Revised 18 August 2020; Accepted 24 August 2020

\begin{abstract}
The Cat $\mathrm{Ba}$ is one of the largest Islands offshore North Vietnam, which is characterized by an abundance of coral reefs in the East and Southeast of the island. The surface sediments are considered the basic elements for the coral ecosystem development. In this study, the authors present some new results studying $\mathrm{pH}$, Eh, mineral composition, and grain size as the basic information for environmental assessment of this area. The results show that the $\mathrm{pH}$ value of the surface sediment varies from 6.90 to 8.09 , with an average of 7.24 while the Eh value of the sediment ranges from 121.10 to $-48.20 \mathrm{mV}$, an average of $-68.39 \mathrm{mV}$, demonstrating a reducing environment. The surface sediments have been classified into 8 size classes: the coarse silt $>$ very coarse silt $>$ medium sand, very fine sand > very coarse sand, fine sand > coarse sand, very fine gravel. Most of the sediments are poorly sorted - very poorly sorted, only a few sedimentary samples are well sorted, moderately sorted, and moderately well sorted. The average mineral composition of the surface sediments consists of: $25 \%$ quartz, $17 \%$ illite, $16 \%$ aragonite, $13 \%$ kaolinite, $10 \%$ calcite, $5 \%$ chlorite, $4 \%$ gothite, $3 \%$ halite, $2 \%$ feldspar and less montmorillonite, and dolomite. These results allowed the researcher to interpret that the sediments have been deposited in a relatively calm environment and the terrigenous sediment sources are dominant over the marine sources. Source marine sediment groups are characterized by coarse grains, high $\mathrm{pH}$, and are rich in carbonate minerals, which have been produced by biological materials. In contrast, the terrigenous sediment group is dominated by fine-grained sediments, rich clay minerals, quartz, and gothite. These fine-grained sediments are commonly distributed in the area and are favorable places for pollutant accumulation.

Keywords: sediment, grain size, mineral, Cat Ba Island.
\end{abstract}

\footnotetext{
* Corresponding author.

E-mail address: nhondh@imer.vast.vn
}

https://doi.org/10.25073/2588-1094/vnuees.4631 


\title{
Đặc điểm trầm tích tầng mặt vùng biển nông ven quần đảo Cát Bà, miền Bắc Việt Nam
}

\author{
Nguyễn Huy Hoàng ${ }^{1}$, Bùi Văn Vượng ${ }^{1}$, Evgenii Egidarev², Vasiliy Zharikov², \\ Lê Anh Xuân ${ }^{1}$, Lại Thị Bích Thủy ${ }^{3}$, Nguyễn Thị Mai Lựu ${ }^{1}$, Nguyễn Đắc Vệ1, \\ Dương Thanh Nghị ${ }^{1}$, Đặng Hoài Nhơn ${ }^{1, *}$ \\ ${ }^{1}$ Viện Tài nguyên và Môi truờng biển, Viện Hàn lâm Khoa học và Công nghệ Việt Nam, \\ 246 Đà Nẵng, Hải Phòng, Việt Nam \\ ${ }^{2}$ Viện Địa lý Thái Bình Dưong, Viện Hàn lâm Khoa học Nga, số 7 đường Radio, Vladivostok, Nga \\ ${ }^{3}$ Trung tâm Phân tích Thí nghiệm Địa chất, Bộ Tài nguyên và Môi truờng, \\ km9, Nguyễn Trãi, Hà Đông, Hà Nội, Việt Nam
}

Nhận ngày 06 tháng 5 năm 2020

Chỉnh sửa ngày 18 tháng 8 năm 2020; Chấp nhận đăng ngày 24 tháng 08 năm 2020

Tóm tắt: Cát Bà là một trong những quần đảo có diện tích lớn nhất ngoài khơi miền Bắc Việt Nam với đặc trưng phân bố nhiều rạn san hô ở phía Đông Nam và phía Nam quần đảo. Các thành tạo trầm tích tầng mặt ở đây được xem là yếu tố nền trong hệ sinh thái rạn san hô. Trong nghiên cứu này, tập thể tác giả trình bày một số kết quả nghiên cứu mới về $\mathrm{pH}$, Eh, thành phần khoáng vật, thành phần cấp hạt trầm tích được sử dụng làm căn cứ đánh giá môi trường của hệ sinh thái này

Kết quả nghiên cứu mới đây của chúng tôi cho thấy: $\mathrm{pH}$ trầm tích dao động từ 6,90 đến 8,09 , trung bình 7,24. Eh trầm tích dao động từ $-121,10$ đến $-48,20 \mathrm{mV}$, trung bình $-68,39 \mathrm{mV}$ thể hiện môi trường khử. Trầm tích phân bố 8 loại theo mức độ phổ biến: bột thô > bột rất thô > cát trung, cát rất mịn > cát rất thô, cát mịn > cát thô, sỏi hạt rất mịn. Phần lớn trầm tích chọn lọc kém đến rất kém, số ít chọn lọc tốt, trung bình tốt, và trung bình. Thành phần khoáng vật trong trầm tích có hàm lượng trung bình: thạch anh $25 \%$, illit $17 \%$, aragonit $16 \%$, kaolinit $13 \%$, canxit $10 \%$, clorit $5 \%$, gotit $4 \%$, halit $3 \%$, fenspat $2 \%$, ngoài ra montmorillonit và dolomit hàm lượng nhỏ.

Từ những kết quả trên có thể luận giải môi trường trầm tích tương đối yên tĩnh và nguồn trầm tích lục địa lớn hơn so với nguồn trầm tích từ biển. Nhóm trầm tích có nguồn gốc biển với kích thước hạt lớn, $\mathrm{pH}$ cao và giàu khoáng vật carbonat trong khi nhóm trầm tích có nguồn gốc lục địa đặc trưng bởi kích thước hạt nhỏ, giàu khoáng vật sét, thạch anh, gơtit. Trầm tích hạt nhỏ chiếm ưu thế trong khu vực và môi trường yên tĩnh nên dễ tích tụ ô nhiễm khi có nguồn tác động.

Tù khóa: Trầm tích; cấp hạt; khoáng vật; đảo Cát Bà.

\section{Mở đầu}

Cát Bà là quần đảo lớn ở ven bờ miền Bắc Việt Nam với hệ sinh thái rạn san hô phân bố phong phú ở phía Đông Nam và phía Nam đảo, hệ sinh thái này vốn nhạy cảm khi môi trường thay đổi nên sẽ chịu nhiều tác động từ nước và trầm tích do vậy cần được quan tâm và cảnh báo để giảm thiểu tác động.

Các nghiên cứu gần đây về chất lượng nước ven bờ quanh đảo Cát Bà cho thấy có biểu hiện

\footnotetext{
* Tác giả liên hệ.

Địa chi email: nhondh@imer.vast.vn

https://doi.org/10.25073/2588-1094/vnuees.4631
} 
ô nhiễm do hoạt động nuôi trồng thủy sản và một phần từ lục địa [1], hàm lượng một số kim loại nặng, hóa chất bảo vệ thực vật trong nước ven bờ Cát Bà cao hơn so với Hạ Long, Bái Tử Long phản ánh tác động từ lục địa tới ven bờ Cát Bà lớn hơn các vùng khác [2].

Ở phía Bắc và phía Tây Bắc của quần đảo Cát Bà được cung cấp trầm tích hệ thống sông Bạch Đằng nên tốc độ lắng đọng trầm tích tăng nhanh hơn so với các vùng giữa vịnh Hạ Long và rìa ngoài do khu vực này ít nhận được nguồn trầm tích từ đất liền chuyển ra. Kết quả đồng vị bền cho thấy ở phía Bắc và phía Tây Bắc đảo thể hiện sự ảnh hưởng của môi trường lục địa chiếm ưu thế [3].

Quanh đảo Cát Bà các nghiên cứu trước đó chỉ ra phân bố trầm tích bột chiếm ưu thế, kèm với nó là hàm lượng kim loại nặng tích lũy trong trầm tích cao $[4,5]$. Thành phần khoáng vật và thành phần cấp hạt trầm tích ở Vịnh Hạ Long tiếp giáp với đảo Cát Bà ở phía Đông và Đông Nam có 9 loại trầm tích, ở Vịnh Hạ Long hàm lượng trung các khoáng vật thạch anh 49\%, illit $=$ kaolinit $=15 \%$, clorit $=$ canxit $=6 \%$, gotit $=$ $5 \%$, montmorillonit $=$ fenspat $=4 \%$ và phân tích cung cấp đã chỉ ra 4 nguồn chủ yếu với mức độ giảm dần: nguồn lục nguyên giàu khoáng vật sét; nguồn từ biển có mặt khoáng vật carbonat từ vụn vỏ sinh vật, nguồn từ phong hóa các đá magma có mặt montmorillonit và nguồn tại chỗ có mặt gơtit được tạo ra theo phương thức hóa học [6].

Bùi Văn Vượng và nnk sử dụng kết quả phân tích tuổi đồng vị ${ }^{210} \mathrm{~Pb}$ và khoáng vật sét theo chiều sâu mẫu ống phóng đã khẳng định trầm tích trong Vịnh Hạ Long có nguồn cung cấp từ hệ thống sông Hồng và nguồn bào mòn xung quanh. Nguồn từ hệ hống sông Hồng đã giảm đi khá nhiều khi đi vào Vịnh Hạ Long thông qua các kênh Cái Tráp, Lạch Huyện, Hoàng Châu và vòng qua đảo Cát Bà. Từ trước 1990 thành phần khoáng vật sét có nguồn gốc từ sông Hồng khá cao, kể từ sau 1990 thì nguồn cung cấp từ phong hóa bóc mòn các đá xung quanh đi vào Vịnh Hạ Long cao hơn [7].

Ở quần đảo Cát Bà và Vịnh Hạ Long sinh vật có tổng số 4622 loài cả ở trên cạn và dưới nước.
Phần biển có 2147 loài, trong đó có 114 loài được ghi trong sách đỏ. Có 7 hệ sinh thái, hệ sinh thái biển điển hình là rạn san hô, rừng ngập mặn, cỏ biển, chúng đang trên đà suy giảm về mức độ đa dạng thành phần loài dưới tác động của con người cũng như môi trường trầm tích nơi chúng sinh sống [8].

Dù đã có thông tin về trầm tích ở phía Bắc và phía Tây, nhưng ở phía Đông, Đông Nam, Tây Nam, Nam đảo Cát Bà nhìn chung còn rất ít, bài báo này bổ sung thông tin còn thiếu gồm có $\mathrm{pH}$, Eh, thành phần cấp hạt, hàm lượng khoáng vật góp phần soi sáng điều kiện môi trường trầm tích ở khu vực này.

\section{Cơ sở tài liệu và phương pháp}

\subsection{Cơ sở tài liệu}

Các số liệu sử dụng cho nghiên cứu này được thu thập từ chương trình khảo sát vào tháng 9 năm 2019, do các nhà địa chất LB. Nga và Việt Nam tiến hành khảo sát 51 trạm (Hình 1 ) và lấy mẫu nghiên cứu, các mẫu thu được bảo quản ở nhiệt độ thường cho các phân tích thành phần cấp hạt và khoáng vật. Thông số $\mathrm{pH}$ và Eh trầm tích được đo bằng máy $\mathrm{pH} 110$ Oakton ở thực địa.

\subsection{Phuơng pháp phân tích}

-Phân tích thành phần cấp hạt trầm tích: Trầm tích thu được đem rửa mặn và loại bỏ vật chất hữu cơ bằng $\mathrm{H}_{2} \mathrm{O}_{2}$ và nước cất, sau đó sàng ướt qua rây $0,063 \mathrm{~mm}$, phần cấp hạt lớn nằm trên rây $0,063 \mathrm{~mm}$ được sấy khô và rây trên các rây có kích thước khác nhau, sau đó cân từng cấp hạt tính hàm lượng phần trăm mỗi cấp hạt, phần cấp hạt nhỏ hơn rây $63 \mu \mathrm{m}$ đem lọc, sấy khô và cân rồi đem phân tích bằng pipet và tính hàm lượng phần trăm từng cấp hạt. Kết quả phân tích của từng cấp hạt tính toán trên phần mềm GRADISTAT, sử dụng phân loại trầm tích theo Folk [9] xác định tên trầm tích (Bảng 1).

- Phân tích thành phần khoáng vật: Mẫu được nghiền nhỏ và rây tới độ hạt $0,074 \mathrm{~mm}$, sau đó lấy khoảng 2 gram cho vào giá đựng mẫu, rồi ấn nhẹ mẫu bằng một tấm kính cỡ $4,5 \times 5 \mathrm{~cm}$ để 
tạo bề mặt phẳng cho mẫu và cao bằng mặt giá đựng mẫu. Nghiên cứu tiến hành trên máy D8 Advance sử dụng bức xạ $\mathrm{Cu}\left(\mathrm{K} \alpha_{1,2}\right)$. Các thông số cài đặt bao gồm hiệu điện thế $35 \mathrm{kV}$, dòng điện $35 \mathrm{~mA}$ bước nhảy $0,015^{\circ} 2 \Theta$, thời gian ngưng 3 giây, và phạm vi quét $5-60{ }^{\circ} 2 \Theta[10]$. Thí nghiệm này được thực hiện tại Trung tâm Phân tích Thí nghiệm Địa chất, Bộ Tài nguyên và Môi trường.

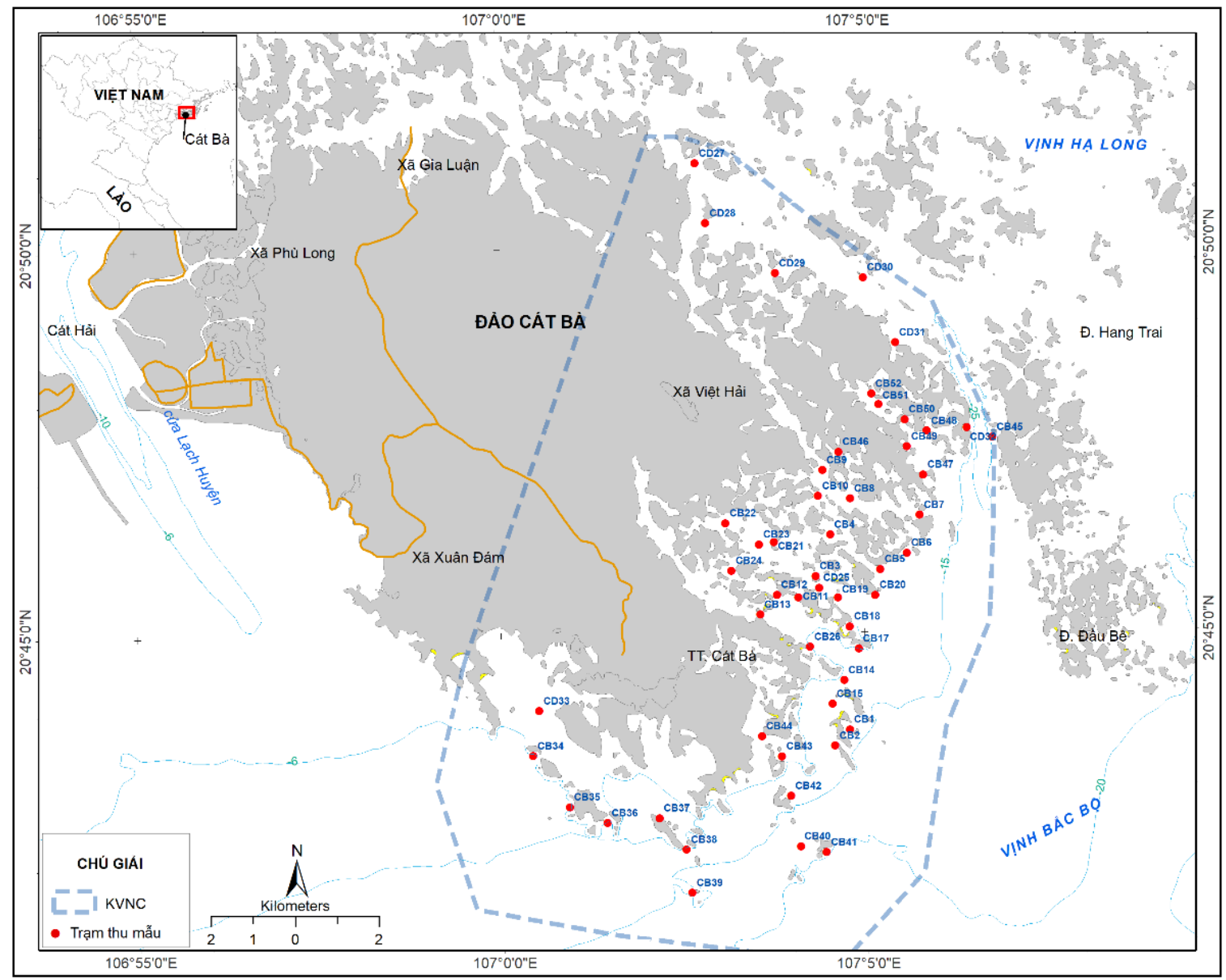

Hình 1. Sơ đồ khảo sát thu mẫu ven bờ Cát Bà.

Bảng 1. Phân loại và mô tả thông số trầm tích theo Folk [9]

\begin{tabular}{|c|c|c|c|c|c|c|c|}
\hline \multicolumn{4}{|c|}{ Trầm tích } & \multicolumn{2}{|c|}{ Độ chọn lọc $\left(\mathrm{S}_{0}\right)$} & \multicolumn{2}{|c|}{ Độ bất đối xứng $\left(\mathrm{S}_{\mathrm{k}}\right)$} \\
\hline Tên & $\begin{array}{c}\mathrm{Md} \\
(\mathrm{mm})\end{array}$ & Tên & $\begin{array}{c}\mathrm{Md} \\
(\mathrm{mm})\end{array}$ & Mức & $\mathrm{S}_{0}$ & Nghiêng về & $S_{k}$ \\
\hline Sạn rất thô & 32 & Cát mịn & 0,125 & Rất tốt & $<1,27$ & Hạt rất mịn & $(-1,0)-(-0,3)$ \\
\hline Sạn thô & 16 & Cát rất mịn & 0,063 & Tốt & $1,27-1,41$ & Hạt mịn & $(-0,3)-(-0,1)$ \\
\hline Sạn trung & 8 & Bột rất thô & 0,031 & Trung bình tốt & $1,41-1,62$ & Đối xứng & $(-0,1)-(0,1)$ \\
\hline Sạn mịn & 4 & Bột thô & 0,016 & Trung bình & $1,62-2,00$ & Hạt thô & $0,1-0,3$ \\
\hline Sạn rất mịn & 2 & Bột trung & 0,008 & Kém & $2,00-4,00$ & Hạt rất thô & $0,3-1,0$ \\
\hline Cát rất thô & 1 & Bột mịn & 0,004 & Rất kém & $4,00-16,00$ & & \\
\hline Cát thô & 0,5 & Bột rât mịn & 0,002 & Cực kỳ kém & $>16,00$ & & \\
\hline Cát trung & 0,25 & Sét & $<0,002$ & & & & \\
\hline
\end{tabular}


- Phân tích thống kê: Số liệu của 16 thông số trầm tích trong 51 mẫu gồm có $\mathrm{pH}$, Eh, thành phần cấp hạt, thành phần khoáng vật được phân tích thống kê trên phần mềm Orgin Pro. 9.1 với các giá trị lớn nhất, nhỏ nhất, trung bình, độ lệch, hệ số tương quan, phân tích thành phần chính (PCA), gom cụm (cluster) nhằm chỉ ra các mối quan hệ giữa các thông số trầm tích và đánh giá nguồn gốc khoáng vật trầm tích ở đảo Cát Bà.

\section{Kết quả nghiên cứu}

\section{1. $p H$ và Eh trầm tích}

pH trầm tích chịu ảnh hưởng của cả môi trường biển và lục địa và giá trị $\mathrm{pH}$ nằm trong ngưỡng của môi trường tự nhiên $(6,5-8,5)$, giá trị $\mathrm{pH}$ dao động từ 6,96 đến 8,09 , trung bình 7,25 (Bảng 2).

Eh trầm tích thể hiện môi trường khử chiếm ưu thế $(\mathrm{Eh}<0 \mathrm{mV})$, giá trị Eh dao động từ 121,10 đến $-48,20 \mathrm{mV}$, trung bình $-68,39 \mathrm{mV}$ (Bảng 2).

\subsection{Thành phần cấp hạt trầm tích}

Phân bố trầm tích tầng mặt ở đảo Cát Bà có 8 loại (Bảng 2, Hình 2) theo thứ tự về mức độ phổ biến: bột thô > bột rất thô > cát trung, cát rất mịn > cát rất thô, cát mịn > cát thô, sỏi rất mịn.

Sỏi rất mịn có đường kính trung bình $(\mathrm{Md})$ dao động từ 2,110 đến $2,2611 \mathrm{~mm}$, trầm tích chọn lọc từ tốt đến rất tốt $\left(\mathrm{S}_{0}=1,20-1,37\right)$, trầm tích nghiêng về hạt rất mịn $\left(S_{\mathrm{k}}=(-4,02)-(-3,05)\right)$.

Cát rất thô với $\mathrm{Md}$ dao động từ 1,018 đến $1,931 \mathrm{~mm}$, trầm tích chọn lọc kém $\left(\mathrm{S}_{0}=2,34\right.$ $3,03)$, chúng nghiêng về hạt rất mịn $\left(\mathrm{S}_{\mathrm{k}}=(-0,88)\right.$ $-(-0,34))$ và đối xứng $\left(\mathrm{S}_{\mathrm{k}}=0,08\right)$.

Cát thô với $\mathrm{Md}$ dao động từ 0,778 dến $0,837 \mathrm{~mm}$, trầm tích chọn lọc kém $\left(\mathrm{S}_{0}=2,65-\right.$ $3,95)$ và nghiêng về hạt rất thô $\left(S_{\mathrm{k}}=0,41\right)$, và nghiêng về hạt mịn $\left(\mathrm{S}_{\mathrm{k}}=-0,27\right)$.

Cát trung với $\mathrm{Md}$ dao động từ 0,274 tới $0,373 \mathrm{~mm}$, trầm tích chọn lọc từ trung bình tốt $\left(\mathrm{S}_{0}\right.$ $=1,54-1,55)$ và kém $\left(\mathrm{S}_{0}=2,19-3,60\right)$, trầm tích nghiêng về hạt thô $\left(S_{\mathrm{k}}=0,14\right)$, hạt rất thô $\left(S_{\mathrm{k}}=\right.$ $0,41)$ và đối xứng $\left(\mathrm{S}_{\mathrm{k}}=0,05-0,09\right)$.

Bảng 2. Giá trị các thông số hóa lý, thông số cấp hạt, các khoáng vật trong trầm tích tầng mặt đảo Cát Bà

\begin{tabular}{|c|c|c|c|c|c|c|c|c|c|c|c|c|c|c|c|c|c|}
\hline $\begin{array}{l}\mathrm{T} \\
\mathrm{T}\end{array}$ & $\begin{array}{l}\text { Ký } \\
\text { hiệׁu } \\
\text { mẫu }\end{array}$ & 莡 & 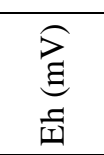 & 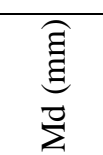 & nீ & जै & $\begin{array}{l}\stackrel{8}{E} \\
\dot{\equiv}\end{array}$ & $\begin{array}{l}\widehat{\theta} \\
\dot{g} \\
\check{g}\end{array}$ & $\begin{array}{l}\hat{\theta} \\
\dot{\theta}\end{array}$ & 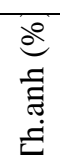 & $\frac{\widehat{d}}{\dot{0}}$ & $\begin{array}{l}\hat{0} \\
\stackrel{0}{0} \\
\stackrel{0}{0}\end{array}$ & $\underbrace{\widehat{d}}_{\tilde{U}}$ & 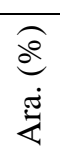 & de & 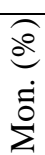 & $\frac{8}{\dot{8}}$ \\
\hline 1 & CB01 & 7,70 & $-96,4$ & 1,018 & 2,37 & $\begin{array}{l}0,08 \\
\end{array}$ & 2 & 2 & 1 & 5 & 0 & 3 & 47 & 38 & 1 & 0 & 0 \\
\hline 2 & CB02 & 8,09 & $-121,1$ & 1,931 & 2,34 & $-0,73$ & 23 & 14 & 6 & 20 & 0 & 2 & 9 & 20 & 2 & 0 & 0 \\
\hline 3 & CB03 & 7,16 & $-63,5$ & 0,180 & 6,72 & 0,36 & 17 & 10 & 5 & 15 & 0 & 2 & 12 & 30 & 3 & 0 & 0 \\
\hline 4 & CB04 & 7,12 & $-60,8$ & 0,036 & 1,90 & $-0,49$ & 20 & 15 & 6 & 29 & 4 & 5 & 5 & 4 & 6 & 0 & 0 \\
\hline 5 & CB05 & 6,98 & $-53,7$ & 0,099 & 6,75 & 0,13 & 17 & 11 & 5 & 37 & 3 & 4 & 1 & 7 & 4 & 0 & 0 \\
\hline 6 & CB06 & 7,86 & $-103,5$ & 1,547 & 2,39 & $-0,34$ & 0 & 1 & 1 & 8 & 0 & 3 & 40 & 40 & 2 & 0 & 0 \\
\hline 7 & CB08 & 7,18 & $-66,4$ & 0,036 & 1,92 & $-0,37$ & 21 & 15 & 7 & 29 & 4 & 4 & 7 & 5 & 5 & 0 & 0 \\
\hline 8 & CB09 & 7,08 & $-58,8$ & 0,035 & 2,93 & $-0,60$ & - & - & - & - & - & - & - & - & -1 & - & - \\
\hline 9 & CB10 & 7,18 & $-64,5$ & 0,031 & 2,01 & $-0,41$ & 19 & 15 & 6 & 31 & 4 & 4 & 4 & 4 & 7 & 0 & 0 \\
\hline 10 & CB11 & 6,99 & $-53,2$ & 0,035 & 2,34 & $-0,24$ & 25 & 20 & 6 & 20 & 0 & 4 & 5 & 5 & 7 & 0 & 3 \\
\hline 11 & CB12 & 7,13 & $-62,1$ & 0,029 & 2,10 & $-0,07$ & 25 & 18 & 6 & 23 & 3 & 5 & 5 & 6 & 5 & 0 & 0 \\
\hline 12 & CB13 & 7,16 & $-63,7$ & 0,144 & 5,76 & 0,34 & 21 & 18 & 6 & 19 & 0 & 3 & 8 & 19 & 2 & 0 & 0 \\
\hline 13 & CB14 & 7,15 & $-63,6$ & 0,052 & 2,88 & 0,00 & 19 & 15 & 6 & 37 & 2 & 5 & 5 & 5 & 2 & 0 & 0 \\
\hline 14 & CB15 & 7,11 & $-61,0$ & 0,030 & 1,96 & $-0,24$ & 24 & 20 & 6 & 28 & 3 & 3 & 3 & 5 & 3 & 0 & 0 \\
\hline 15 & CB16 & 7,32 & $-75,6$ & 0,778 & 2,65 & 0,41 & - & - & - & - & - & - & - & - & - & - & - \\
\hline 16 & CB17 & 7,09 & $-59,0$ & 0,026 & 2,00 & $-0,09$ & 19 & 16 & 6 & 36 & 4 & 5 & 4 & 0 & 4 & 0 & 0 \\
\hline 17 & CB18 & 7,35 & $-73,4$ & 0,357 & 2,19 & 0,14 & 5 & 2 & 2 & 4 & 0 & 0 & 17 & 64 & 2 & 0 & 0 \\
\hline
\end{tabular}




\begin{tabular}{|c|c|c|c|c|c|c|c|c|c|c|c|c|c|c|c|c|c|}
\hline 18 & B19 & 7,34 & $-75,6$ & 0,316 & 1,55 & 0,05 & 2 & 1 & 0 & 4 & 0 & 2 & 23 & 65 & 1 & 0 & 0 \\
\hline 19 & B20 & 7,85 & $-105,9$ & 2,261 & 1,20 & $-4,02$ & 5 & 2 & & 14 & 0 & 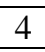 & 43 & 25 & 2 & & 0 \\
\hline 20 & $\mathrm{~B} 21$ & 7,27 & $-69,4$ & 0,026 & 2,70 & $-0,03$ & 23 & 18 & & 25 & & 5 & 4 & 6 & & & 0 \\
\hline 21 & 322 & 7,22 & $-66,3$ & 0,026 & 2,70 & 0,01 & 21 & 18 & & 27 & & & & & & & \\
\hline 22 & 323 & 17 & $-64,6$ & 025 & 2,33 & 0,19 & 23 & 17 & & 26 & & & & & & & \\
\hline 23 & 324 & 7,07 & $-58,3$ & 019 & 2,13 & 0.23 & 24 & 17 & & 28 & & & & & & & \\
\hline 24 & 325 & 19 & $-66,1$ & 085 & 7,65 & $\overline{0,66}$ & 17 & 14 & & 25 & & & & 19 & & & \\
\hline 25 & B26 & 07 & $-58,6$ & 027 & 2,72 & $-0,05$ & 23 & 18 & & 27 & & & & 5 & & & \\
\hline 26 & B27 & 7,07 & $-58,2$ & 0,031 & 2,92 & $-0,02$ & 21 & 17 & & 33 & & & & 5 & & & 0 \\
\hline 27 & 32 & 7,15 & $-63,5$ & & 7,21 & 0,57 & 19 & 16 & & 34 & & & & 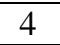 & & & 0 \\
\hline 28 & 329 & 7,17 & 4,5 & & 2,17 & 0,12 & 21 & 15 & & 35 & & & & & & & 0 \\
\hline 29 & 330 & 5 & 34,3 & 2,110 & 1,37 & -3, & 2 & 2 & & 31 & & & 27 & 21 & & & 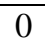 \\
\hline 30 & 331 & 7,12 & $-60,5$ & 031 & 2,89 & $-0,43$ & 25 & 20 & & 29 & & & 3 & ( & & & 0 \\
\hline 31 & 332 & 7,39 & $-79,0$ & 274 & 1,54 & 0,09 & 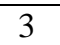 & 3 & & 6 & & . & 22 & 55 & & & 0 \\
\hline 32 & $\mathrm{~B} 33$ & 7,15 & $-63,7$ & 034 & 2,12 & $-0,29$ & 23 & 14 & & 42 & & & 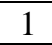 & 3 & 3 & & 0 \\
\hline 33 & 234 & 7,11 & -614 & & 2,03 & $-0,01$ & 22 & 18 & & 38 & 5 & & & 0 & 3 & & 0 \\
\hline 34 & & 7,05 & 57,5 & & 2,01 & $-0,1$ & 25 & 18 & & 33 & & & & & 4 & & 0 \\
\hline 35 & 336 & 6,9 & $-48,2$ & & 2,43 & 0, & - & & & - & & & & & & & - \\
\hline 36 & 337 & 7,22 & 57,1 & 080 & 3,49 & 0,0 & 21 & 1 & & 31 & & & & 10 & & & 0 \\
\hline 37 & 338 & 7,14 & 51,9 & & 1,98 & -0 , & 22 & 17 & & 32 & & & & 3 & & & 0 \\
\hline 38 & CB39 & 7,08 & $-58,1$ & & 4,51 & 0,22 & 15 & 14 & & 29 & & 2 & 10 & 14 & 2 & & 5 \\
\hline 39 & P40 & 7,18 & -644 & & 4,88 & 0,01 & 18 & 15 & & 28 & $\overline{4}$ & 2 & 7 & s & 2 & & 7 \\
\hline 40 & & 6,96 & -48 & & 1,96 & -0 & 24 & 16 & & 34 & 4 & & & & 5 & & 0 \\
\hline 41 & 342 & 03 & -56 & & 1,99 & $-0,3$ & 22 & 17 & & 34 & & & & & 5 & & 0 \\
\hline 42 & 343 & 39 & 76,7 & 837 & 3,95 & $-0,27$ & 15 & 14 & & 19 & & & 12 & 25 & 2 & & 0 \\
\hline 43 & CB44 & 7,68 & $-93,4$ & 09 & 1,41 & 0,2 & 2 & 2 & & 37 & & & 16 & 35 & 1 & & 0 \\
\hline 44 & CB45 & 7,32 & $-73,8$ & & 3,03 & $-0,88$ & 13 & 10 & & 17 & & 2 & 31 & 13 & 2 & 0 & 0 \\
\hline 45 & CB46 & 7,18 & $-65,0$ & & 3,6 & 0,41 & 23 & 16 & & 30 & 3 & 5 & 5 & 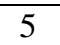 & 3 & ( & 0 \\
\hline 46 & 041 & 7,35 & $-75,0$ & & 2,22 & -0 & 7 & 2 & & 7 & & & 20 & 5. & & & 0 \\
\hline 47 & & 22 & 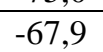 & & 2,09 & $-0,36$ & 21 & 14 & & 31 & & & & 11 & & & 0 \\
\hline 4 & & 29 & & & 2,71 & $-0,18$ & 19 & 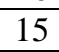 & & 36 & & & & & & & 0 \\
\hline 49 & & 7,21 & 6,7 & & 2,31 & 0,03 & 23 & $\overline{1^{\prime}}$ & & 25 & & & & & 7 & & O \\
\hline 50 & & 7,33 & $-74,3$ & & 2,07 & $-0,25$ & 23 & 18 & & 27 & & & 5 & 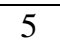 & 4 & & 0 \\
\hline 51 & CB52 & 7,11 & $-61,7$ & 0,026 & 1,73 & 0,09 & 21 & 17 & 7 & 23 & 4 & 4 & 5 & 10 & 6 & 0 & 0 \\
\hline
\end{tabular}

Ill. - Illit; Kao. - Kaolinit; Clo. - Clorit; Th.anh - Thạch anh; Fel. - Fenspat; Gơt. - Gotit; Ca. - Canxit; Ara. - Aragonit; Ha. - Halit; Mon. - Montmorillonit; Dol. - Dolomit; (-) - không phân tích

Cát mịn với $\mathrm{Md}$ dao động từ 0,144 tới $0,180 \mathrm{~mm}$, trầm tích chọn lọc rất kém $\left(\mathrm{S}_{0}=4,88\right.$ - 6,72), chọn lọc tốt $\left(\mathrm{S}_{0}=1,41\right)$, trầm tích nghiêng về hạt rất thô $\left(\mathrm{S}_{\mathrm{k}}=0,34-0,35\right)$, hạt thô $\left(\mathrm{S}_{\mathrm{k}}=0,20\right)$ và đối xứng $\left(\mathrm{S}_{\mathrm{k}}=0,01\right)$.

Cát rất mịn có $\mathrm{Md}$ dao động từ 0,080 đến $0,115 \mathrm{~mm}$, trầm tích chọn lọc kém đến rất kém $\left(\mathrm{S}_{0}=3,49-7,65\right)$, trầm tích nghiêng về hạt rất thô $\left(S_{k}=0,57-0,66\right)$, hạt thô $\left(S_{k}=0,13-0,22\right)$, đối xứng $\left(\mathrm{S}_{\mathrm{k}}=0,08\right)$.

Bột rất thô có $\mathrm{Md}$ dao động từ 0,031 đến $0,052 \mathrm{~mm}$, trầm tích chọn lọc từ trung bình $\left(\mathrm{S}_{0}=\right.$
1,90 -1,99) đến kém $\left(\mathrm{S}_{0}=2,01-2,93\right)$, trầm tích nghiêng về hạt rất mịn $\left(\mathrm{S}_{\mathrm{k}}=(-0,60)-(-0,30)\right)$, hạt mịn $\left(S_{\mathrm{k}}=(-0,29)-(-0,24)\right)$, đối xứng $\left(\mathrm{S}_{\mathrm{k}}=(-\right.$ $0,02)-(0,00))$

Bột thô có $\mathrm{Md}$ dao động từ 0,019 đến $0,031 \mathrm{~mm}$, trầm tích chọn lọc kém $\left(\mathrm{S}_{0}=2,01\right.$ $2,89)$, chọn lọc trung bình $\left(\mathrm{S}_{0}=1,73-2,00\right)$, trầm tích nghiêng về hạt mịn $\left(\mathrm{S}_{\mathrm{k}}=(-0,25)-(-0,15)\right)$, hạt thô $\left(\mathrm{S}_{\mathrm{k}}=0,12-0,19\right)$, hạt rất mịn $\left(\mathrm{S}_{\mathrm{k}}=(-0,43)\right.$ $-(-0,30))$, đối xứng $\left(\mathrm{S}_{\mathrm{k}}=(-0,09)-(0,09)\right)$. 


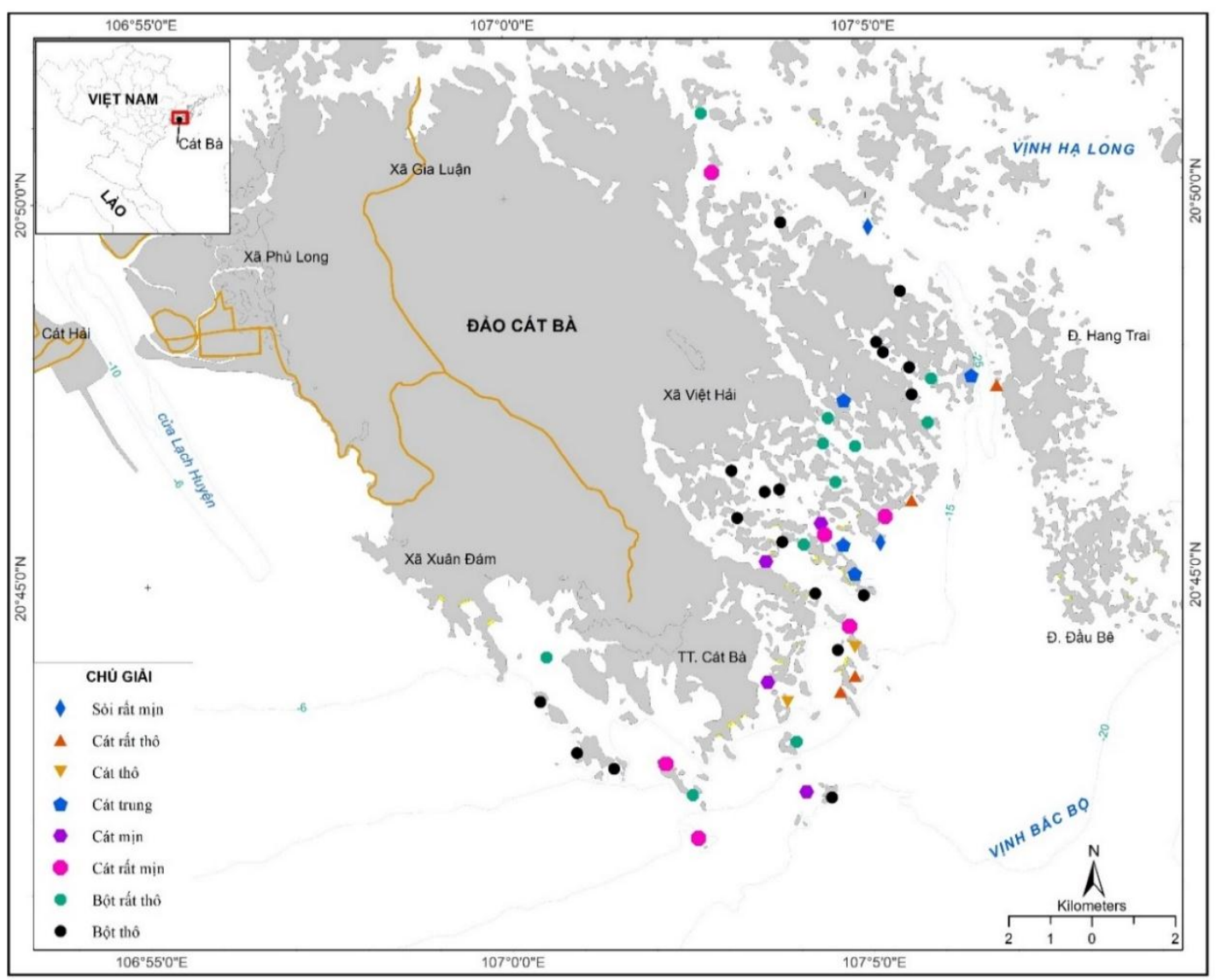

Hình 2. Sơ đồ phân bố trầm tích ven bờ Đảo Cát Bà.

\subsection{Thành phần khoáng vật trong trầm tích}

Khoáng vật trong trầm tích có hàm lượng trung bình thứ tự giảm dần như sau: thạch anh > illit $>$ aragonit $>$ kaolinit $>$ canxit $>$ clorit $>$ gotit $>$ halit $>$ felspat (Bảng 2).

Illit hàm lượng cao nhất trong số khoáng vật sét, chúng dao động từ 0 đến $25 \%$, trung bình $18 \%$, phân bố phổ biến trong trầm tích ở hầu hết các trạm.

Kaolinit hàm lượng dao động từ 1 đến $20 \%$, trung bình $14 \%$, giống như illit hàm lượng kaolinit có mặt hầu hết các trạm khảo sát.

Clorit hàm lượng nhỏ hơn illit và kaolinit, hàm lượng dao động từ 0 đến $7 \%$, trung bình $5 \%$, dù có hàm lượng không lớn nhưng có mặt trong hầu hết các mẫu thu được.
Montmorillonit hàm lượng thấp không đáng kể, chúng chỉ xuất hiện trong một vài mẫu gần khu vực bến Bèo.

Thạch anh hàm lượng cao nhất trong số khoáng vật trong trầm tích, dao động từ 4 đến $42 \%$, trung bình $26 \%$. Mức độ phổ biến thạch anh cao nhất trong số khoáng vật có mặt trong trầm tích.

Fenspats hàm lượng nhỏ, dao động từ 0 đến $5 \%$, trung bình $2 \%$. Mặc dù có mặt nhưng hàm lượng thẩp trong hầu hết các mẫu, mức độ phổ biến không cao.

Gơtit hàm lượng thấp, dao động từ 0 đến $6 \%$ và trung bình $4 \%$, dù hàm lượng thấp nhưng có mặt trong nhiều vị trí ở đảo Cát Bà.

Halit có mặt trong hầu hết các mẫu với hàm lượng từ 1 đến $7 \%$, trung bình $3 \%$, hàm lượng 
halit thường cao trong trạm có hàm lượng khoáng vật sét cao.

Aragonit hàm lượng phổ biến sau thạch anh và illit, chúng dao động từ 0 đến $65 \%$, trung bình $14 \%$. Chúng có mặt trong hầu hết các mẫu, ở một số trạm đo được hàm lượng aragonit có hàm lượng cao trong số trầm tích hạt thô, và hàm lượng thấp trong các trầm tích hạt mịn.

Canxit hàm lượng cao nhưng thấp hơn hàm lượng aragonit, dao động từ 1 đến $47 \%$, trung bình $10 \%$. Giống như aragonit, canxit có mặt phổ biến trong các mẫu, hàm lượng khá cao trong các mẫu có kích thước hạt thô như cát và sỏi và thấp hơn trong các mẫu bột.

Dolomit hàm lượng ít phổ biến, chúng chỉ xuất hiện trong một vài mẫu trong số thu được, hàm lượng cao nhất là $7 \%$ còn lại đều hàm lượng thấp.

\section{Thảo luận}

\subsection{Thành phần độ hạt, khoáng vật phản ánh nguồn gốc và động lực môi truờng}

Ven bờ đảo Cát Bà phân bố 8 loại trầm tích, phổ biến là bột tiếp đến là cát và sỏi thì ít phổ biến (Bảng 2), chúng hầu hết chọn lọc kém và rất kém phổ biến hơn là chọn lọc trung bình và trung bình tốt, điều đó phản ánh điều kiện động lực yên tĩnh với dòng chảy nhỏ và sóng nhỏ.

Trầm tích hạt thô như sỏi và cát liên quan đến các khoáng vật nhóm carbonat có nguồn gốc vụn vỏ sinh vật, trong khi khoáng vật sét chiếm hàm lượng cao hơn đi kèm với trầm tích hạt nhỏ trong môi trường trầm tích tương đối yên tĩnh. $\mathrm{pH}$ và Eh trầm tích phản ánh môi trường chịu nhiều sự chi phối từ lục địa với giá trị $\mathrm{pH}<7,2$ chiếm tổng số $31 / 51$ điểm khảo sát (Bảng 2), còn lại 20 điểm có giá trị $\mathrm{pH}>7,2$.

Theo nghiên cứu trước đó thì Vịnh Hạ Long nằm sát vùng nghiên cứu nhận được nguồn cung cấp từ sông Hồng bởi chỉ thị khoáng vật sét và tỷ số của các khoáng vật sét, bên cạnh đó cũng nhận được từ quá trình phong hóa bóc mòn các đá xung quanh tăng nhanh kể từ năm 2000 đến 2016 [4]. Nguồn cung cấp trầm tích ven bờ Hải Phòng nhận được từ hệ thống sông Hồng chảy qua các sông Văn Úc, Lạch Tray, Cửa Cấm đặc trưng hàm lượng khoáng vật sét khá lớn [6] thể hiện mức độ tương đồng cao khi so với bãi triều Bàng La và Ngọc Hải về thành phần khoáng vật sét.

Ở đảo Cát Bà trầm tích thể hiện 2 nguồn cung cấp trầm tích chủ yếu, nguồn từ biển có kích thước hạt lớn, nhiều khoáng vật argagonit, canxit và dolomit. Nguồn từ lục địa đặc trưng bởi kích thước hạt nhỏ, nhiều illit, kaolinit, thạch anh và clorit mang từ lục địa ra biển.

\subsection{Tưong quan giũa các thông số trầm tích}

Các thông số trầm tích thể hiện mức tương quan từ hoàn hảo $(\mathrm{R}=1)$, tương quan mạnh $(\mathrm{R}$ $=0,75-0,95)$, tương quan trung bình $(\mathrm{R}=0,5$ $0,75)$ và tương quan yếu $(R=0,25-0,5)$. Hệ số tương quan thể hiện 2 kiểu tương quan thuận và nghịch (Hình 3).

Tương quan thuận thể hiện ở 3 mức là mạnh, trung bình, yếu. Tương quan thuận phản ánh trầm tích có cùng nguồn cung cấp từ lục địa hoặc cùng nguồn cung cấp từ biển đều thể hiện khá rõ. Nguồn lục địa là các yếu tố chi phối gồm khoáng vật sét (illit, kaolinit, clotrit), thạch anh, fenspat, các khoáng vật tại chỗ có tương quan trung bình là halit với khoáng vật sét và yếu với fenspat và thạch anh. Nguồn biển là aragonit - canxit - Md - pH thể hiện qua tương quan thuận mức trung bình và mạnh. Môi trường trầm tích yên tĩnh thể hiện tương quan thuận yếu giữa $S_{0}$ và $S_{k}$.

Tương quan nghịch thể hiện ở 4 mức là hoàn hảo, mạnh, trung bình, yếu. Tương quan nghịch phản ánh sự quan hệ tương phản về nguồn gốc và tương phản điều kiện môi trường, thông số trầm tích có nguồn gốc biển tương quan nghịch thông số nguồn gốc lục địa, thông số đặc trưng cho các yếu tố động lực thể hiện bằng động lực mạnh ngược với động lực yếu.

Trong 16 thông số trầm tích thì montmorillonit và dolomit gần như không có mối tương quan có ý nghĩa với thông số khác, ở mức không phụ thuộc tuyến tính vào các thông số khác, với hàm lượng nhỏ và không chi phối vào đặc trưng của môi trường trầm tích ở đảo Cát Bà. 


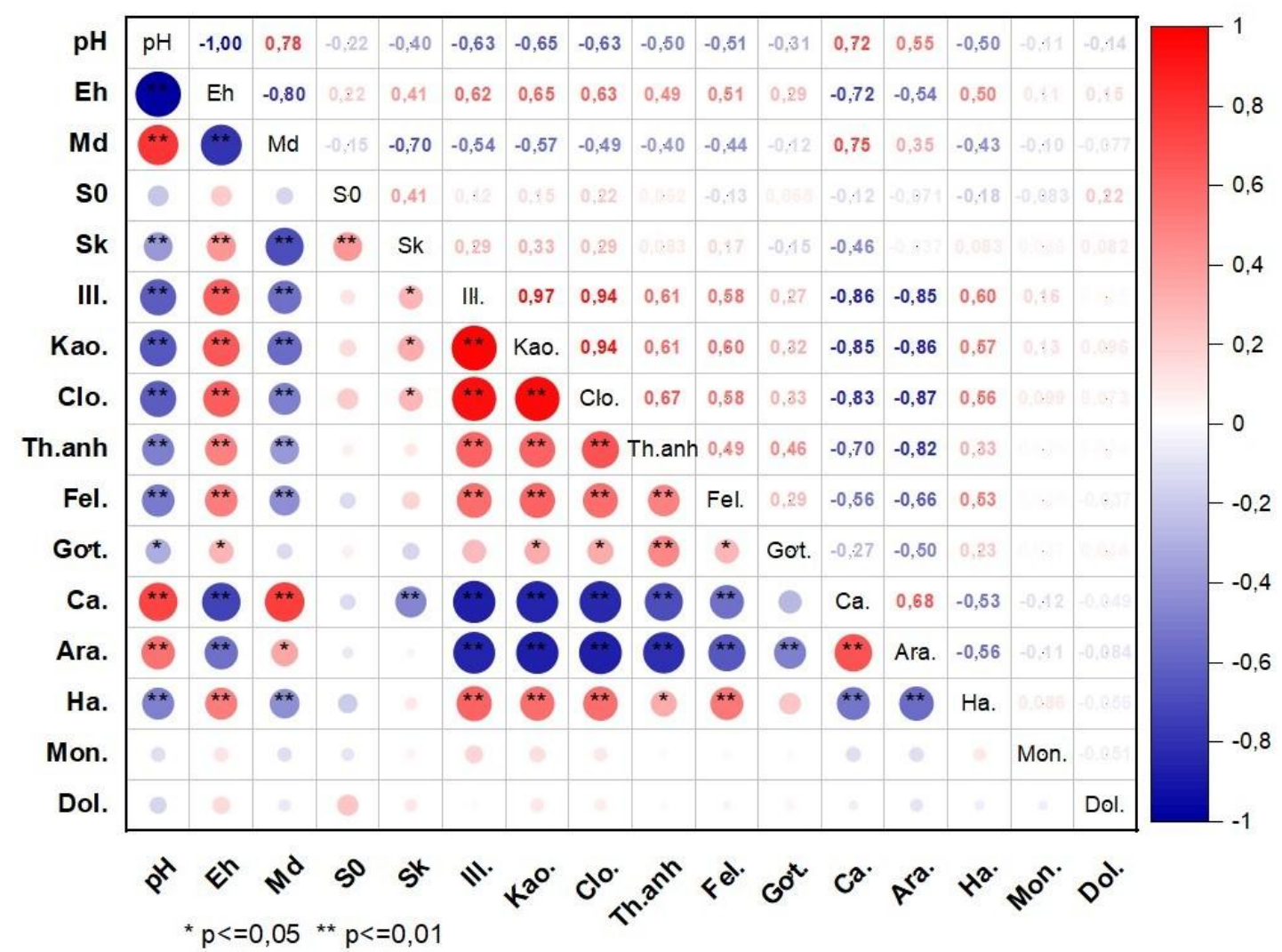

Số mẫu = 48; ** p <0,01 (độ chính xác 99\%); *p < 0,05 (độ chính xác 95\%); Ill. - Illit; Kao. - Kaolinit; Clo. - Clorit; Th.anh - Thạch anh; Fel. - Fenspat; Gơt. - Gơtit; Ca. - Canxit; Ara. - Aragonit; Ha. - Halit; Mon. - Montmorillonit; Dol. - Dolomit.

Hình 3. Ma trận tương quan giữa các thông số trầm tích ven bờ Cát Bà.

\subsection{Thành phần chính chi phối môi trường trầm tích}

Kết quả phân tích thành phần chính (TPC) của 16 thông số trầm tích, có 3 thành phần chính (TPC 1, TPC 2, TPC 3) chi phối tập hợp trầm tích Cát Bà với giá trị riêng của từng thành phần chính TPC 1, TPC 2, TPC 3 lần lượt là 7,8, 2,0 và 1,3 (Bảng 3 , Hình 4). TPC 1 chi phối 48,8\% đặc trưng môi trường với các giá trị riêng của thông số trầm tích trong thành phần chính $\geq 0,3$ gồm $\mathrm{pH}$, Eh, illit, kaolinit, clorit, canxit, aragonit. TPC 2 chi phối $12,4 \%$ đặc trưng môi trường với các thông số có giá trị riêng $\geq 0,3$ gồm $\mathrm{Md}, \mathrm{S}_{0}, \mathrm{~S}_{\mathrm{k}}$. TPC 3 chi phối $8,2 \%$ đặc trưng môi trường gồm: gơtit, halit, montmorillonit, và dolomit.

Dù hàm lượng cao và phổ biến trong trầm tích tầng mặt nhưng thạch anh lại có giá trị riêng thấp hơn các thông số khác trong 3 thành phần chính chi phối chủ đạo, cho thấy nhận dạng môi trường trầm tích của thạch anh ở ven bờ Cát Bà ít hơn so với các khoáng vật khác. Động lực ở khu vực này khá yên tĩnh thể hiện bằng thạch anh có tương quan thuận với khoáng vật sét (illit, kaolinit, clorit) điều này cho thấy thạch anh và khoáng vật sét cùng nguồn cung cấp và trong điều kiện yên tĩnh nên độ chọn lọc trầm tích kém.

Từ hình 3 dựa trên 16 thông số trầm tích được phân tích thành phần chính đã chia nguồn cung cấp vật liệu trầm tích thành 2 là nguồn lục địa và nguồn biển. Nguồn gốc từ lục địa gồm các thông số nằm ở phía phải của Hình 4 lấy giá trị 0 của TPC 1 làm gianh giới, đặc trưng bởi các thông số ưu thế là illit, kaolinit, clorit, Eh, $\mathrm{S}_{0}, \mathrm{~S}_{\mathrm{k}}$, gơtit, thạch anh. Nguồn gốc biển, phân bố ở phía trái Hình 4 lấy giá trị 0 của TPC 1 là gianh giới, đặc trưng bởi thông số ưu thế là $\mathrm{pH}, \mathrm{Md}$, canxit, và aragonit. 
Bảng 3. Giá trị riêng các thành phần chính và các thông số trầm tích

\begin{tabular}{|c|c|c|c|c|c|c|c|}
\hline TPC & Giá trị riêng & Phương sai (\%) & Phương sai tích lũy & Thông số & TPC 1 & TPC 2 & TPC 3 \\
\hline 1 & 7,8 & 48,8 & 48,8 & $\mathrm{pH}$ & $\mathbf{- 0 , 3 0}$ & 0,20 & 0,04 \\
\hline 2 & 2,0 & 12,4 & 61,2 & $\mathrm{Eh}$ & $\mathbf{0 , 3 0}$ & $-0,22$ & $-0,05$ \\
\hline 3 & 1,3 & 8,2 & 69,5 & $\mathrm{Md}$ & $-0,26$ & $\mathbf{0 , 3 5}$ & 0,24 \\
\hline 4 & 1,0 & 6,1 & 75,6 & $\mathrm{~S}_{0}$ & 0,06 & $\mathbf{- 0 , 4 0}$ & 0,51 \\
\hline 5 & 0,9 & 5,9 & 81,5 & $\mathrm{~S}_{\mathrm{k}}$ & 0,15 & $\mathbf{- 0 , 5 5}$ & $-0,14$ \\
\hline 6 & 0,9 & 5,3 & 86,8 & Illit & $\mathbf{0 , 3 3}$ & 0,09 & $-0,02$ \\
\hline 7 & 0,6 & 3,7 & 90,5 & Kaolinit & $\mathbf{0 , 3 3}$ & 0,07 & 0,04 \\
\hline 8 & 0,5 & 3,0 & 93,5 & Clorit & $\mathbf{0 , 3 3}$ & 0,09 & 0,11 \\
\hline 9 & 0,4 & 2,7 & 96,2 & Thạch anh & 0,26 & 0,20 & 0,21 \\
\hline 10 & 0,3 & 1,9 & 98,1 & Felspat & 0,25 & 0,18 & $-0,16$ \\
\hline 11 & 0,1 & 0,9 & 99,0 & Gơtit & 0,14 & 0,27 & $\mathbf{0 , 3 5}$ \\
\hline 12 & 0,1 & 0,5 & 99,6 & Canxit & $\mathbf{- 0 , 3 3}$ & 0,06 & 0,07 \\
\hline 13 & 0,0 & 0,3 & 99,8 & Aragonit & $\mathbf{- 0 , 3 0}$ & $-0,29$ & $-0,19$ \\
\hline 14 & 0,0 & 0,1 & 99,9 & Halit & 0,23 & 0,18 & $\mathbf{- 0 , 3 0}$ \\
\hline 15 & 0,0 & 0,0 & 99,9 & Montmorillonit & 0,05 & 0,02 & $\mathbf{- 0 , 3 0}$ \\
\hline 16 & 0,0 & 0,0 & 100,0 & Dolomit & 0,03 & $-0,19$ & $\mathbf{0 , 4 8}$ \\
\hline
\end{tabular}

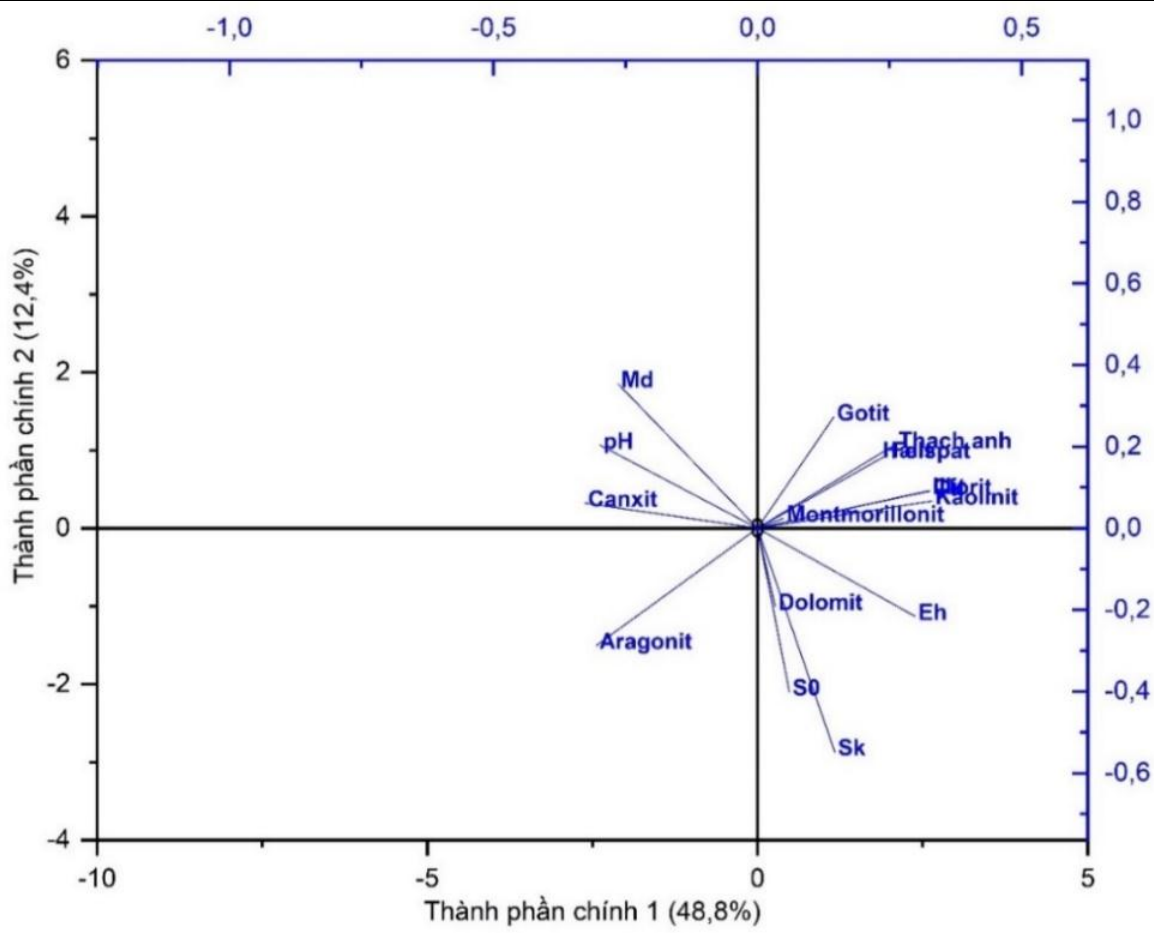

Hình 4. Các thành phần chính và quan hệ giữa các tham số trầm tích.

\subsection{Các nhóm trầm tích và đặc trung của nhóm}

Phân tích gom cụm (cluster) thực hiện nhằm phân chia các nhóm với các đặc trưng môi trường gống nhau được xếp vào cùng nhóm, với 16 thông số và 48 mẫu chia thành 2 nhóm, có 3 mẫu không phân tích thành phần khoáng vật gồm CB09, CB16, CB25 nên không có mặt trong phân tích gom cụm (Bảng 4, Hình 5).

Phân tích gom cụm cho 48 trạm chia thành 2 nhóm. Nhóm 1 với 7 trạm đặc trưng cho nguồn 
gốc biển với các giá trị $\mathrm{pH}>7,5$, đường kính trầm tích là cát rất thô $(\mathrm{Md}=1,583 \mathrm{~mm})$, chọn lọc trầm tích kém, trầm tích nghiêng về hạt rất nhỏ (Bảng 4), các khoáng vật sét thấp trong khi khoáng vật carbonat có hàm lượng cao. Nhóm 2 với 41 trạm đặc trưng cho nguồn gốc lục địa với $\mathrm{pH}<7,2$, trầm tích là cát rất mịn $(\mathrm{Md}=$ 0,081mm), khóang vật sét cao trong khi khoáng vật carbonat thấp (Bảng 4, Hình 5).
Phân tích gom cụm cho 16 thông số trầm tích, các thông số được chia 2 nhóm đặc trưng cho mỗi kiểu nguồn cung cấp trầm tích ở vùng ven bờ Cát Bà. Nhóm 1 gồm có thông số $\mathrm{pH}-$ canxit - aragonit - Md đặc trưng nguồn gốc biển. Nhóm 2 gồm các thông số kaolinit - illit - thạch anh - clorit - Eh - fenspat - halit - $\mathrm{S}_{0}-\mathrm{S}_{\mathrm{k}}-$ dolomit - montmorillonit đặc trưng nguồn gốc lục địa (Hình 5).

Bảng 4. Giá trị trung bình các thông số trong mỗi nhóm trầm tích ở ven bờ đảo Cát Bà

\begin{tabular}{|c|c|c|c|c|c|c|c|c|c|c|}
\hline Nhóm & Số lượng trạm & $\mathrm{pH}$ & $\mathrm{Eh}(\mathrm{mV})$ & $\mathrm{Md}(\mathrm{mm})$ & $\mathrm{S}_{0}$ & $\mathrm{~S}_{\mathrm{k}}$ & Illit (\%) & $\begin{array}{c}\text { Kaolinit } \\
(\%)\end{array}$ & $\begin{array}{c}\text { Clorit } \\
(\%)\end{array}$ & $\begin{array}{c}\text { Thạch } \\
\text { anh } \\
(\%)\end{array}$ \\
\hline 1 & 7 & 7,67 & $-94,53$ & 1,583 & 2,38 & $-1,32$ & 9 & 6 & 3 & 16 \\
\hline 2 & 41 & 7,17 & $-64,48$ & 0,081 & 2,93 & $-0,04$ & 19 & 15 & 5 & 27 \\
\hline
\end{tabular}

Bảng 4. (tiếp)

\begin{tabular}{|c|c|c|c|c|c|c|c|}
\hline Nhóm & $\begin{array}{c}\text { Felspat } \\
(\%)\end{array}$ & $\begin{array}{c}\text { Gơtit } \\
(\%)\end{array}$ & $\begin{array}{c}\text { Canxit } \\
(\%)\end{array}$ & $\begin{array}{c}\text { Aragonit } \\
(\%)\end{array}$ & $\begin{array}{c}\text { Halit } \\
(\%)\end{array}$ & $\begin{array}{c}\text { Montmorillonit } \\
(\%)\end{array}$ & $\begin{array}{c}\text { Dolomit } \\
(\%)\end{array}$ \\
\hline 1 & 0 & 4 & 30 & 26 & 2 & 0 & 0 \\
\hline 2 & 2 & 4 & 6 & 12 & 4 & 0 & 0 \\
\hline
\end{tabular}

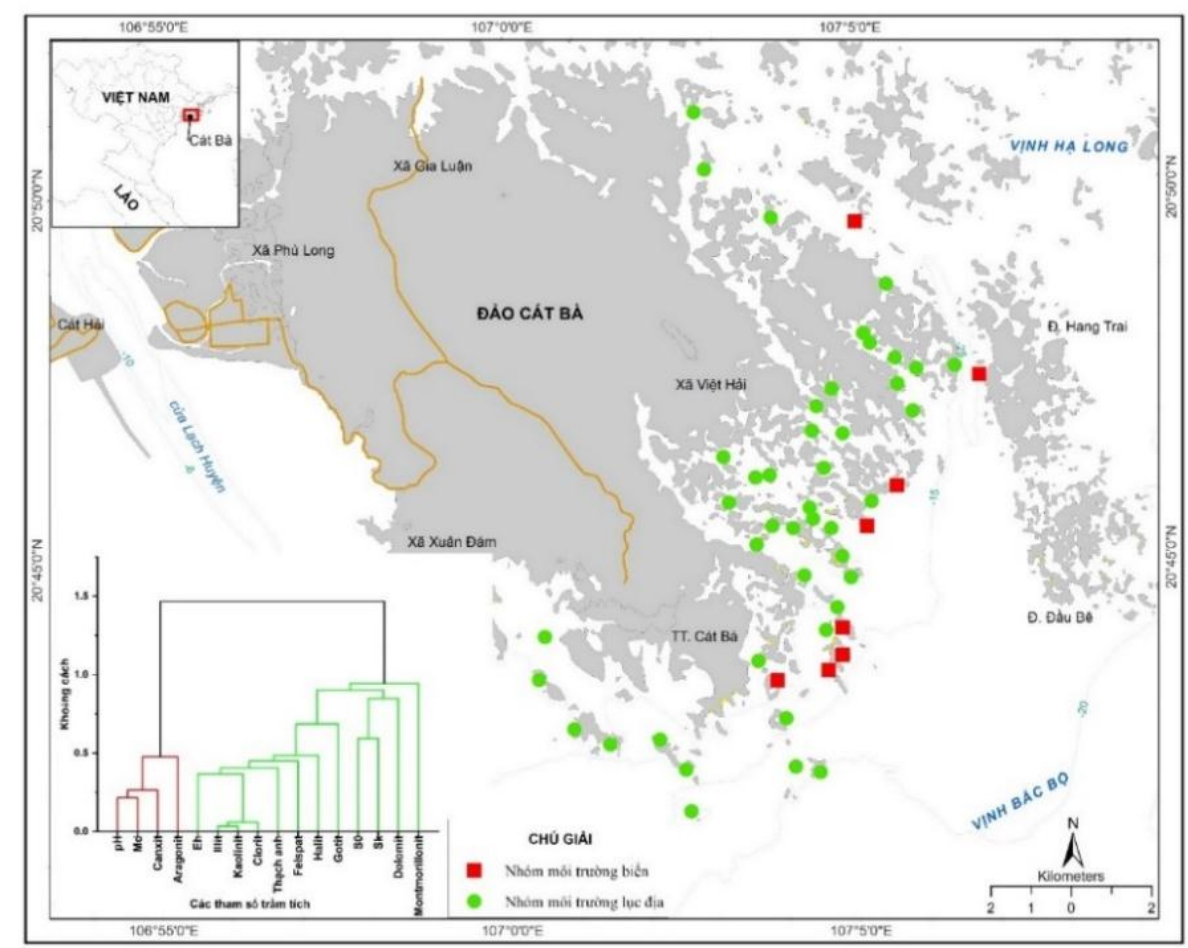

Hình 5. Các nhóm trầm tích và thông số trầm tích. 


\section{Kết luận}

Trầm tích ven bờ đảo Cát Bà phân bố 8 loại là sỏi rất mịn, cát rất thô, cát thô, cát trung, cát mịn, cát rất mịn, bột rất thô, bột thô. Trầm tích chủ yếu chọn lọc kém đến rất kém, số ít chọn lọc trung bình tốt và trung bình, bột chiếm ưu thế, sau đến cát và sỏi.

Giá trị pH dao động từ 6,96 đến 8,09 , trung bình 7,25. Giá trị Eh dao động từ -121,10 đến $48,20 \mathrm{mV}$, trung bình $-68,39 \mathrm{mV}$. Sỏi rất mịn có $\mathrm{Md}$ từ 2,110 đển $2,2610 \mathrm{~mm}$, cát rất thô với $\mathrm{Md}$ từ 1,018 đến $1,931 \mathrm{~mm}$, cát thô với $\mathrm{Md}$ từ 0,778 đến $0,837 \mathrm{~mm}$, cát trung với $\mathrm{Md}$ từ 0,274 tới $0,373 \mathrm{~mm}$, cát mịn với $\mathrm{Md}$ từ 0,144 tới $0,180 \mathrm{~mm}$, cát rất mịn với Md 0,080 đến $0,115 \mathrm{~mm}$, bột rất thô với Md từ 0,031 đến $0,052 \mathrm{~mm}$, bột thô có Md từ 0,019 đến $0,031 \mathrm{~mm}$.

Khoáng vật trong trầm tích có illit từ 0 đến $25 \%$ và trung bình $18 \%$, kaolinit từ 1 đến $20 \%$ và trung bình 14 , clorit từ 0 đến $7 \%$ và trung bình $5 \%$, montmorillonit hàm lượng thấp không đáng kể, thạch anh từ 4 đến $42 \%$ và trung bình $26 \%$, fenspat từ 0 đến $5 \%$ và trung bình $2 \%$, gotit từ 0 đến $6 \%$ và trung bình $4 \%$, halit từ 1 đến $7 \%$ và trung bình $3 \%$, aragonit từ 0 đến $65 \%$ và trung bình $14 \%$, canxit từ 1 đến $47 \%$ và trung bình $10 \%$, dolomit hàm lượng không đáng kể.

Môi trường trầm tích ven bờ Cát Bà chịu ảnh hưởng lục địa và biển, môi trường lục địa chi phối chiểm ưu thể, môi trường biển chi phối thứ yếu. Trầm tích hạt mịn chiếm ưu thế hơn so với hạt thô, điều kiện môi trường trầm tích tương đối yên tĩnh. Trầm tích thuận lợi cho tích tụ chất ô nhiễm nếu nguồn cung cấp mang chất ồ nhiễm hàm lượng cao sẽ tác động xấu đến rạn san hô.

\section{Lời cảm ơn}

Bài báo nhận được sự hỗ trợ của Viện Hàn lâm Khoa học và Công nghệ Việt Nam (QTRU02.03/19-20), Viện Tài nguyên và Môi trường biển (TMB.2020. ĐTCS1), Phân Viện Viễn Đông thuộc Viện Hàn lâm Khoa học Nga (A comprehensive program of basic scientific research of the Far East Branch of the Russian
Academy of Sciences "Far East" for 20182020", project VANT 19-019). Các tác giả cảm ơn các cơ quan đã hỗ trợ kinh phí thực hiện, cảm ơn phản biện đã đọc và nhận xét góp ý bản thảo.

\section{Tài liệu tham khảo}

[1] L.T. Son, T.Q. Thu, N.C. Thanh, P.H. Giang, Environmental pollution at typical marine fish cage culture areas: case study at Cat $\mathrm{Ba}$ - Hai Phong, Vietnam Journal of Marine Science and

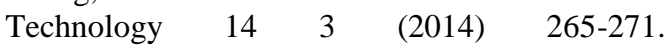
https://doi.org/10.-15625/1859-3097/14/ 3/3983 (in Vietnamese).

[2] C.T.T. Trang, D.C. Thung, L.V. Nam, P.T. Kha, N.V. Bach, D.H. Ngoc, Assessment of Sea Water Quality in some Limestone Island and Archipelagos areas, Viet Nam, VNU Journal of Science: Earth and Environmental Sciences, 361 (2020) 70-78. https://doi.org/10.25073/2588-1094 /-vnuees. 4556.

[3] D.H. Nhon, V.T.T. Hanh, J. Matthews, B.V. Vuong, D.V. Huy, N.D. Khang, N.M. Luu, N.D. Ve, P.V. Luong, P.S. Hai, Sedimentation Rates and Sediment Supply Sources to Ha Long Bay in the Past 150 Years, VNU Journal of Science: Earth and Environmental Sciences 322 (2016) 46-56 (in Vietnamese).

[4] H.H. Hieu, R. Swennen, V. Cappuyns, E. Vassilieva, G. Neyens, M. Rajabali, T.T. Van, Assessment on Pollution by Heavy Metals and Arsenic Based on Surficial and Core Sediments in the Cam River Mouth, Haiphong Province, Vietnam, Soil and Sediment Contamination: An International Journal 22 (2013) 415-432. https://doi.org/10.1080/15320383.2013.733445.

[5] H.H. Hieu, R. Swennen, V. Cappuyns, E. Vassilieva, G. Neyens, M. Rajabali, T.T. Van, Geogene versus anthropogene origin of trace metals in sediments in Cua Luc estuary and $\mathrm{Ha}$ Long Bay, Vietnam, Estuaries and Coasts 36 (2013) 203-219. https://doi.org/10.1007/s12237012-9562-3.

[6] D.H. Nhon, T.D. Thanh, L.T.B. Thuy, B.V. Vuong, N.D. Ve, Distribution of mineral compositions in surface sediment in the Ha Long Bay, Viet Nam, in: The Third National Proceeding in Marine Geology. Publishing House for Science and Technology, Ha Noi, 2019, pp. 80-89 (in Vietnamese).

[7] B.V. Vuong, Z. Liu, T.D. Thanh, C.A. Huh, D.H. Nhon, N.D. Ve, D.V. Huy, Initial results of study on sedimentation rate, sediment source to the $\mathrm{Ha}$ 
Long Bay: evidence from the ${ }^{210} \mathrm{~Pb}$ and ${ }^{137} \mathrm{Cs}$ radiotracer, Vietnam Journal of Marine Science and Technology 161 (2016) 54-63. https://doi. org/10.15625/1859-3097/16/1/6527 (in Vietnamese).

[8] D.C. Thung, N.D. Ngai, D.V. Thao, N.V. Sinh, D.M. Dong, Marine biodiversity in Ha Long bay and Cat $\mathrm{Ba}$ archipelago, Vietnam Journal of Marine Science and Technology 193 (2019) 363369. https://doi.org/10.15625/1859-3097/19/3/13174 (in Vietnamese).

[9] R.L. Folk, Petrology of sedimentary rocks, Hemphill Publishing Company, Austin, Texas,
1980. https://repositories.lib.utexas.edu/handle/ $2152 / 22930$.

[10] ICDD International Center for Diffraction Data, 2004. PDF database release. Data Sets $1-50$ plus 70-88, USA.

[11] D.H. Nhon, N.T.M. Luu, L.T.B. Thuy, N.N. Nam, N.H. Hoang, B.M. Quan, Mineral compositions and grain sizes of sediments in intertidal zone in Northern Vietnam, Vietnam Journal of Marine Science and Technology 19 3A (2019) 63-75. https://doi.org/10.15625/18593097/-19/3A/14292 (in Vietnamese). 